\title{
TEORÍAS DEL ARCHIVO, FORMAS DE LA HUIDA. SOBRE TEORÍA DEL ALMA CHINA DE CARLOS A. AGUILERA*
}

\author{
ARCHIVE'S THEORIES, WAYS TO SLIP AWAY. \\ ON TEORÍA DEL ALMA CHINA BY CARLOS A. AGUILERA
}

IRINA GARBATZKY

Universidad Nacional de Rosario. Rosario, Argentina.

irinagarbatzky@conicet.gov.ar

\begin{abstract}
Resumen: El artículo se propone definir las coordenadas y el funcionamiento de los signos orientales en la literatura del escritor cubano Carlos A. Aguilera, en el marco de una investigación mayor, acerca de los retornos de un archivo soviético en la literatura cubana actual. Tomando como punto de partida las desestabilizaciones del referente realista emergidas durante los años noventa (Mateo Palmer, 1995), señalamos primero, en los inicios de la poética del autor, los significantes eurasiáticos y las referencias que formulan la búsqueda de construcción de un territorio literario alternativo al proyecto nacional. Desde esta perspectiva se analiza luego el libro Teoría del alma china (2006). Focalizamos nuestra lectura en el modo en que el libro escenifica los problemas del archivo en la literatura latinoamericana, especialmente del archivo de la modernidad, así como la predominante presencia de animales y desfiguraciones de lo humano, como crítica a los modos de relación entre los cuerpos y el Estado.
\end{abstract}

Palabras clave: Literatura cubana, orientalismo y literatura latinoamericana, literatura y biopolítica, archivo y sistemas discursivos.

Abstract: The article proposes to define the characteristics of Oriental signs in the literature of Cuban writer Carlos A. Aguilera, under further investigation, about the return of a Soviet archive in Cuban literature. Taking as a starting point the destabilizations of realistic literature emerged during the nineties (Mateo Palmer, 1995), we note first, at the beginning of the poetics of the author, Eurasians signifiers and the references made by the search for construction of an alternative literary territory to the national project. From this perspective the book Teoría del alma china (2006) is then analyzed. We focus reading in the staging of file problems in Latin American

\footnotetext{
* Este artículo es parte del proyecto de investigación "Políticas del cuerpo en la literatura cubana contemporánea. Inscripciones y retornos de un archivo soviético", que llevo adelante en IECH-UNR CONICET.
} 
literature, especially the file of modernity and the predominant presence of animals and disfigurement of the human, as critical to the modes of relationship between the bodies and the State.

Keywords: Cuban Literature, Orientalism and Latin American literature, literature and biopolitics, archives and discursive systems.

Recibido: 21.04.2016. Aceptado: 05.09.2016

T A obra del escritor cubano Carlos A. Aguilera - cuya producción li$\mathcal{L}$ teraria comienza en los años noventa, durante la crisis del "Período especial" y con la caída de la Unión Soviética como horizonte- diseña un espacio singular dentro de la literatura cubana actual. Se trata de una zona que circunscribe sus imaginarios geográficos en el Este, la gran Eslavia; un oriente eurasiático, soviético y chino. Los restos, las persistencias, en el arte, la literatura y la cultura del vínculo entre La Habana y Moscú -que vienen siendo objeto de estudios de una serie de investigaciones (Puñales Alpízar, 2013; Loss, 2013; Rojas, 2009)- podrían trazar un problema para leer la literatura de este autor y también de otros casos de su generación. En varios momentos de la literatura de Aguilera, de Rolando Sánchez Mejías o de José Manuel Prieto, por apenas mencionar algunos nombres, dicho imaginario eurasiático retorna como un archivo por construir, y coloca en el centro la preocupación por el futuro y por el vínculo entre los cuerpos y el Estado.

El sentido que Michel Foucault le otorgó al concepto de "archivo" en su Arqueología del saber no se orienta al acopio de documentación sobre un período histórico, sino a la ley que permite la emergencia de un sistema discursivo. Por lo tanto, sería importante preguntarnos si, más allá de una topología artificial que reescribiría, en el fin del siglo XX, los impulsos de los exotismos del siglo XIX, la remisión a dichos paisajes del Este no involucraría a su vez una pregunta por los modos en que se sistematizan los discursos sobre la relación entre los individuos y el poder. Siguiendo esta perspectiva, sería posible leer en la literatura de Aguilera la construcción de una máquina interpretativa y archivística de la sovietización cultural. Mi hipótesis es que los modos que poseen estos escritores para archivar los años de mayor sovietización de la cultura de la isla, siguen la vertiente 
del extrañamiento y la extranjerización. Los paisajes eurasiáticos no vendrían a acudir únicamente como parábola de los totalitarismos de Estado, sino que, una vez que la mirada del escritor se posa sobre ellos, éstos se convierten en formas de extrañamiento sobre la propia identidad y el territorio. E inclusive, yendo un paso más allá, sería posible sostener que en estos paisajes, lo que se desbarata, junto al ideal de nación, es el ideal de lo humano, como propietario de la posibilidad de construir un nuevo mundo. La predominancia de los animales en la literatura de Aguilera viene, en consecuencia, a plantear nuevas preguntas sobre las implicancias de las políticas del cuerpo, tanto en sus vertientes negativas como afirmativas; esto es, tanto desde aquellas políticas que actúan sobre los cuerpos de los individuos mediante formas disciplinares, como desde aquellas otras que manan de lo vivo como creación de nuevos modos de organización y comunidad (Valdecantos, 2009).

Para argumentar estas observaciones me situaré, en esta oportunidad, en la novela de Aguilera Teoría del alma china, que, si bien publicada en 2006, mantiene vigentes las coordenadas de una poética que surge hacia finales de los años noventa y sus preguntas referidas a la identidad y al territorio, ya presentes desde sus primeros libros. En el siguiente apartado trazaré dicho recorrido de lectura, para entrar luego en su análisis específico.

\section{El Este como fuga}

En Ella escribía poscrítica (1995), un libro que tempranamente recabó los efectos de la posmodernidad en la isla, la crítica Margarita Mateo Palmer recorría, desde una Habana precaria, periférica, sumergida en la crisis del "Período especial", los apuntes del debate en torno a la modernidad y la posmodernidad en la teoría europea y norteamericana, para preguntarse cómo situar en él a la literatura insular. Aunque la parodia, la intertextualidad o la simulación, como procedimientos de lo posmoderno por excelencia, podían encontrarse en autores como Severo Sarduy o Cabrera Infante, ello no respondía a lo posmoderno como una conceptualización cuya aplicabilidad sería mundial, sino que se leía en consonancia con la propia 
historia de la literatura cubana, la cual tradicionalmente había puesto en juego los límites entre el archivo y la ficción, cuestionando profundamente la idea de una identidad como esencia original.

En el caso de los años noventa, además, buena parte de la literatura se relacionaba con los procesos de desestimación del referente que había sido canónico durante las décadas del sesenta y setenta ${ }^{1}$. La ruptura del canon que comenzó entonces, cuando se observaron los pliegues o las rajaduras del modelo revolucionario, colocó en primer plano el conflicto acerca de cómo definir la realidad, "en un nivel de la escritura bien alejado del referente” (Mateo Palmer, 1995: 153).

Oriente ingresaría así en la literatura cubana postmoderna como parte de esa puesta en distancia que, como las princesas asiáticas de Julián del Casal, las chinerías de Lezama Lima o el hinduismo de Severo Sarduy, venían a hablar menos de un orientalismo en la clave exotista y colonizadora que describió Edward Said (2002)2, que como formas de expresar una cri-

\footnotetext{
${ }^{1}$ Recordemos que el realismo social se había convertido en un valor clave para la literatura cubana de la década del setenta (la década de mayor injerencia soviética en el arte), recuperando a la novela policial como género que privilegiadamente tomaba para sí los puntos clave del realismo socialista. Según el excelente desarrollo de Duanel Díaz en La revolución congelada, el género policial en la narrativa cubana de los años setenta permitía alcanzar el ideal lucacksiano del realismo socialista como "arte profundo, capaz de desentrañar lo subyacente en los fenómenos sociales e históricos” (2013: 169). El debate que sucede por esos años, en cuyo seno residía el lugar límite para los intelectuales dentro de la Revolución, apuntaba directamente al problema de la autonomía de la obra de arte; en palabras de Díaz, "la crítica cubana de los setenta insistió hasta la saciedad en la antinomia entre el contenido revolucionario y la innovación burguesa de la forma" (170). La misión de la literatura no implicaba un realismo meramente superficial -de ahí el complejo lugar de lo testimonial o lo documental-, sino que debía revelar "el orden oculto de lo real, esa trama que conduciría al futuro socialista" (171).

${ }^{2}$ Resulta interesante para ello la observación que hace César Sepúlveda (1996) al situar la diferencia de los latinoamericanos Lezama Lima y Octavio Paz en su acercamiento a Oriente por su posicionamiento periférico, ya que allí se distingue de la voluntad hegemónica esgrimida por las miradas de Occidente para construir su alteridad. En los casos latinoamericanos, argumenta, la alteridad es constitutiva de los propios procesos nacionales e identitarios (y en el caso de Cuba, más aún, considerando que lo chino compone el tercer elemento étnico en su población, a partir de la importación masiva de chinos para el trabajo agrícola a mediados del siglo XIX). Es por esto que Sepúlveda sostiene: "Las estrategias orientalistas que, según Edward Said, han servido a la cultura occidental para 'exotizar' o exorcizar el Oriente y, en último término, negarlo, resultan inútiles en este contexto. Muy al contrario, la tarea de los intelectuales hispanoamericanos será precisamente la inversa: la búsqueda de semejanzas, la construcción de un puente metafórico entre culturas que abra las puertas a un discurso integrador" (137).
} 
sis (Mateo Palmer comparaba, en el recuerdo de Casal, un fin de siglo con otro $)^{3}$. El oriente en la literatura cubana de los noventa involucraba así los procesos de indagación respecto de la propia identidad en términos de un proceso transcultural.

En el caso de Aguilera sería difícil ubicar, al modo de Lezama Lima, el apetito que incorpore la cultura universal en una teleología insular. En el Este diseñado en su literatura, se presentan una serie de funciones en tensión. En primer lugar, la creación de un territorio otro, aunque dentro de la isla. Una creación cuya misma construcción -expuesta muchas veces como artefacto- viene a explicitar los procesos estéticos de las utopías modernas. Volver a construir un territorio, una nación y una comunidad parece ser, en este sentido, una de sus obsesiones reiteradas, justamente a partir de la extrapolación de los restos de una lengua en ruinas hacia otro continente. Cabría preguntarse si acaso la lengua arruinada que aparece en sus poemas (arruinada por lo rota, desarticulada, deshilvanada en sílabas), no converge asimismo hacia la tensión, -ya varias veces señalada respecto de las ruinas habaneras-, entre la demolición y el desmembramiento, consolidando una estética que pone en marcha el anhelo de una nueva literatura. Para observarlo en el aspecto material de su poesía, podríamos anotar el agenciamiento de elementos visuales y tipográficos. En sus dos primeros libros, Retrato de A. Hopper y su esposa (1996) así como en Das Kapital (1997a), sus poemas forman verdaderas construcciones hacia abajo y en vertical, o diseñan madrigueras, imágenes de recorridos, huidas ${ }^{4}$.

Las primeras figuraciones de Oriente que Aguilera traza en sus primeros poemarios, instauran entonces una duplicidad entre la constitución de

3 "ya Julián del Casal había pronosticado los finales de este siglo en los finales del siglo anterior, cuando escribía a su bella desconocida -disfrazada de princesa asiática-, que lo miraba desde la altura de su elefante colosal, bajo un balaquino de raso rojo, bordeado de oro" (Mateo Palmer, 1995: 84-85).

${ }^{4} \mathrm{El}$ uso de elementos visuales y símbolos en la poesía de Aguilera sería objeto de un artículo separado. Coloco un pequeño ejemplo entre varios que podrían cotejarse en sus libros, para observar el desmembramiento de la lengua y el trabajo de construcción vertical en Retrato de A. Hopper y su esposa: La / tarde / en / que / Hooper / , / Andrew / alias / " / el / granjero / " / Hopper [...] mostró / ( / por / única / ocasión / ) / su / " / Libro / de / comentarios / sobre / Nietzsche / " / [...] / no / pudo / , / siquiera / , / definir / , / el / valor / político / de / su / libro / , / y / , / por / lo / tanto / , / el / valor / - / llamado / - / exacto / de / su / libro (1996: 11-14). 
un espacio y sus formas de fuga. En el prólogo del primer libro, en efecto, el autor daba cuenta de su poesía como una "máquina" cuya lógica buscaba

elaborar un relato que se sitúa en el afuera del pensar-Institución. Elaborar, un relato, que se sitúe (en el afuera) de lo que ha sido pensado como Institución. [...] En la Literatura Cubana apenas hay: Problemas. Quiero decir: apenas existe la Literatura como Problema. Como Juego. Como Transgresión. Como Goce. Todo ha sido centralizado. Llevado a su máximo de Ontologización. Todo ha sido convertido en Territorio. Territorio que ha devenido parcela ridícula de aburrimientos. Territorio que ha devenido estancamiento edípico del saber. (9)

En estos libros iniciales no sólo la excentricidad espacial y la experimentación tipográfica abren la salida hacia "el afuera de la Institución". Ésta también se presenta mediante la referencia a las antípodas geográficas del trópico. Por ejemplo, el único y largo poema que compone Retrato de A. Hopper y su esposa, lleva por índice al final, entre paréntesis: "(San Petersburgo, 1994)". O, en el caso de Das Kapital -amén de la referencia al título de Marx, en el propio título-, la fecha: "Calcuta, 1993", al final de la "Advertencia".

Sería difícil acotar el sentido de estas referencias al verosímil realista de un viaje por parajes exóticos. La anotación de la fecha y la ciudad apunta hacia un gesto que se volverá central en la literatura del autor: construir para la escritura una espacialidad diseñada con nuevos límites, que permita pensar la propia condición del intelectual durante ese nuevo interregno que supuso la crisis pos-soviética. "Para trazar un límite al pensamiento tendríamos que ser capaces de pensar ambos lados de este límite (gren$z e$ ), y tendríamos por consiguiente que ser capaces de pensar lo que no se puede pensar", sostiene en la "Advertencia" de Das Kapital (5). En adelante, la invención de referentes soviéticos y asiáticos, como la Gran Eslavia en la que viven los personajes de la novela El imperio Oblómov (2014), la China maoísta de Teoría del alma china, los paisajes alemanes, polacos, checos en donde transcurren las piezas teatrales de Discurso para una madre muerta (2012) o Clausewitz y yo (2014), se convertirán en una patria extraterritorial de su poética. Un desplazamiento que no se cifra ya en la adopción de una lengua extranjera para la escritura de la propia obra como han sido los casos señalados por George Steiner (2000)-, sino que se 
sostiene en el despliegue de otros panoramas para envolver el ambiente de sus obras; un gesto sumamente teatral, sin duda, que alcanza a tanto a sus novelas como a su poesía.

Idalia Morejón Arnaiz, en dos artículos centrales para el análisis de este problema en la obra de Aguilera (2008 y 2011), entiende que sus textos deben leerse a través de la clave del exotismo, o mejor, del "exotismo ideológico", por cuanto la presencia de otras culturas en la literatura latinoamericana contemporánea los vuelve espacios de liberación, de fuga ideológica y estética. Morejón Arnaiz los diferencia de una perspectiva europeizante y colonial, observando que se trata de un "juego no europeo en conexión con otras civilizaciones" (2008: 1), que tendría relación, a la vez, con los modos de inscripción de la literatura cubana en la literatura mundial y en las series que pueden trazarse con obras brasileras, argentinas o cubanas, de nuevos exotismos ${ }^{5}$.

Junto a estos restos del exotismo, entonces, observamos que estos paisajes eurasiáticos presentan una función alegórica, metáforas o parábolas de una sovietización tropical. La China maoísta o la Gran Eslavia soviética construyen pequeñas fábulas que, un poco en clave de humor negro, y, otro poco, en clave de denuncia, elaboran el trauma moderno de la opresión de los Estados totalitarios sobre los intelectuales ${ }^{6}$.

\footnotetext{
${ }^{5}$ Inserta en los procesos de globalización de la literatura mundial, la literatura latinoamericana del siglo XXI sobrepasa los marcos tercermundistas con los cuales había sido leída por Europa durante los años sesenta. Según Morejón Arnaiz, la literatura latinoamericana actual, en su incorporación a una condición literaria global, piensa su lugar en el mundo sin barreras y Europa deviene exótica ante sus ojos. "Para la América Latina que transita entre el final del siglo XX y estos primeros años del XXI, el éxodo hacia el Norte, y el acceso directo a zonas geográficas excéntricas sin la mediación de la mirada europea, son los elementos fundamentales que dan soporte a esta tendencia" (2008: 1).

${ }^{6}$ Morejón Arnaiz enfatiza, a su vez, que los primeros borradores de Teoría del alma china fueron escritos en Cuba, antes de la partida de su autor. De este modo, argumenta, "Teoría del alma china, independientemente del lugar donde su autor comienza a escribirla (Cuba), donde la termina (Austria), o donde la publica (México, Croacia, Alemania, República Checa), es un libro marcado por su lugar de origen: el insilio cubano de un intelectual que aplica cínicamente los códigos y juegos de silencio para criticar al totalitarismo de Estado y zafarse de la aplicación de los discursos nacionalistas a la interpretación de su obra" (2011: 156).
} 


\section{Hacia China}

Desde las primeras décadas del siglo XX, tanto la ciudad de Moscú como Pekín funcionaron como el significante de la metrópolis singular que condensaba los proyectos libertarios de la modernidad. Los viajes intelectuales que hacia allí se orientaban, desde Walter Benjamin hasta César Vallejo, desde Juan L. Ortiz hasta Bernardo Kordon, y tantos otros, eran, en buena medida, viajes de aprendizaje. Sylvia Saítta (2007) señala la cualidad testimonial que adquiría para estos intelectuales el hecho de ver y palpar el futuro del mundo y Raúl Antelo (2001) acuñó la idea de Moscú como "marco de lo moderno" para leer dichos itinerarios. El desplazamiento involucraba el encuentro con lo radicalmente otro -la vida absolutamente divergente del capitalismo-, pero aún dentro de esta diferencia radical persistía el proyecto moderno de transformación total de la vida.

En el extremo opuesto de dicha hora histórica, se hallaría la novela Teoría del alma china. El cubano no sólo no atestigua la posibilidad de transformación social en curso, sino que el viaje a China supone la ocasión para la confección crítica de un archivo, e incluso, para la crítica del Archivo en sí misma. La figuración del Oriente en Aguilera se ubica, de este modo, más cerca del Oriente marginal y periférico que Daniel Link detectó como matriz productiva para la literatura de Paul Bowles y de William Burroughs: aquellos otros escritores viajeros por un oriente fronterizo (Tánger), cuyo periplo ya no restauraba las utopías modernas sino que apuntaba a señalar la acumulación de sus ruinas7.

La primera condición problemática que expone Teoría del alma china como testimonio por Oriente proviene de la artificialidad de cualquier re-

\footnotetext{
7 En "Tánger: ruina de la modernidad", Daniel Link abordaba de qué modo ese espacio abyecto y marginado, frontera internacional desde mediados de siglo, se había convertido en la imagen de las ruinas de los proyectos modernos, particularmente para Paul Bowles y William Burroughs, que residieron allí durante cierto tiempo. Desde esta periferia oriental, ambos reescribieron y renovaron profundamente la novela norteamericana, habitando una franja en donde se acumulaban las experimentaciones estéticas del siglo XX y su aspiración a ser convertidas en mercancías globales. Dice Link: "Frente a las peregrinaciones utópicas de comienzos de siglo los viajeros que pasan por Tánger o que permanecen allí jamás encuentran nada que puedan relacionar con las utopías clásicas (estéticas o políticas) del siglo. [...] Tánger, en las versiones alucinatorias o mitológicas de Burroughs y de Bowles, es la ruina de la modernidad. No un límite o un certificado de defunción, sencillamente la ruina: lo que queda como índice de que algo estuvo"(1997: 166-174. Las cursivas son mías).
} 
lato de viaje. "Un viaje, por muy detallado que sea, también es un hecho de ficción”, sostiene el narrador durante el periplo. Así, dos polos, el del detalle realista y el de la ficción, irán construyendo en tándem la narración, y quien relata resulta una nueva figura del "testigo de vista"; un personaje situado entre el turista y el investigador. La "teoría" comienza como un manual para viajeros, un falso manual al estilo Lonely Planet (Morejón Arnaiz, 2008). El primer apartado, (“Teoría del alma china I") resulta una descripción pormenorizada y mundana de la sociedad y el paisaje, de las ocupaciones del cuerpo (los contorsionistas, los fumaderos de opio), las artesanías, las bebidas y las comidas típicas, los sitios (los karaokes, literalmente "cajas de repetición”), las figuraciones del espacio (las laberínticas carreteras, las autopistas, los museos y los templos). Pero, poco a poco, la escritura del turista y del curioso observador pasará a la del espía e investigador y lo que al comienzo se mostraba con ingenuidad o gracia, expone, gradualmente, una cualidad opresiva y monstruosa. El observador va acercándose a la figura del extranjero "kafkiano", a medida que toma en cuenta su relación con un poder central. De hecho, Teoría del alma china recuerda en varias ocasiones a "En la colonia penitenciaria" (In der Strafkolonie): en aquel relato un explorador innominado se desempeñaba como testigo necesario, no sólo para que el relato tenga lugar, sino para que las autoridades puedan exhibir su maquinaria ${ }^{8}$. Una escena similar ocurre en el texto de Aguilera, especialmente cuando el viajero visita una penitenciaría (también situada en una colonia, la de los japoneses en la China, luego el narrador dirá que la China entera funciona como una cárcel). La mirada de Aguilera focaliza las superficies y su tono adopta la apariencia de banalidad o de alegre regeneración. Podríamos decir que, siguiendo a Kafka, la violencia naturalizada se esboza como mueca grotesca. En la visita a la penitenciaría, por ejemplo, una alusión velada a la tortura hace intervenir al juego de máscaras y el sarcasmo:

Dos presos modelos, la población penal tiene varias categorías según su propio comportamiento, nos explicaron las maneras en que funcionaba

\footnotetext{
${ }^{8}$ Así comienza el relato de Kafka: “-Es un aparato singular- dijo el oficial al explorador, y contempló con cierta admiración el aparato que le era tan conocido. El explorador parecía haber aceptado sólo por cortesía la invitación del comandante para presenciar la ejecución de un soldado condenado por desobediencia e insulto hacia sus superiores" (1976: 25).
} 
el proyecto regenerativo "que los volvería a hacer pensar como hombres en sociedad", y los diferentes documentales y charlas sobre realidad china que le daban algunos días a la semana. Cuando preguntamos cuál fue el último que vieron, gritaron: iiMao es la encarnación de la patria!!

Por supuesto, el personal administrativo empezó a aplaudir.

Otras de las cosas interesantes fueron las salas tecnológicas, con varios equipos de voltaje apretados contra la pared y muchas sillas, camas, mesitas de color blanco, correas, etc. [...] Al interesarnos en las camas: unas al lado de otras y todas junto a los equipos de voltaje, tartamudearon un poco pero aseguraron que tenía que ver con la creatividad: si una persona se agota ahí puede descansar un poco... Con lo que el personal administrativo movió de nuevo asertivamente la cabeza y rompió a aplaudir (Aguilera, 2006: 98-99).

Como decíamos más arriba, el viaje efectúa un pasaje de la mirada turística hacia las descripciones del encierro y el castigo; las anécdotas del libro, de manera sucesiva, van internándose en espacios cada vez más reducidos y vigilados. El "alma” china escenifica de este modo una teoría sobre la relación entre la letra y el poder de la ley, entre la letra y el castigo. Más aún, una postulación de cómo la eficacia de la letra circunscribe, da forma y devora a los individuos. En la China del libro de Aguilera, como en el cuento de Kafka, no existen cuerpos que queden por fuera de la escritura de la ley que los explica y los condena, no existen cuerpos por fuera de sus modos de registro y archivación. La novela podría leerse en la serie que elaboró Roberto González Echevarría (2000), al pensar en la etiología de la narrativa moderna latinoamericana. El protagonismo del soporte documental que despliega el texto -los informes, los manuscritos inéditos, los archivos del investigador y del espionaje, los registros penitenciarios, a la par de los registros cartográficos de la China e incluso las fotografías de la China que el guardia del aeropuerto de Beijing no los deja llevar al país de regreso (37) - nos hace pensar en aquellas "ficciones de archivo" que, de acuerdo con González Echevarría, simulaban los procesos de imitación de textos dotados de autoridad; documentos que reiteran el "lenguaje de la autoridad encarnada en el discurso de la ley, cuyo depósito y símbolo es el archivo de Simancas" (9). Según González Echevarría, la narrativa latinoamericana contemporánea generó sus propios mitos mediante el regreso al espacio arcóntico que guarda sus orígenes legales y los discursos del conocimiento y el poder. En la China de Aguilera, este regreso supone una fuerte tematiza- 
ción de la articulación entre la letra y el cuerpo, del archivo como forma de constricción disciplinar, que somete el territorio a la lengua y su escritura.

De este modo, así como en el cuento de Kafka el extranjero observaba en vivo el proceso de condena y castigo de un preso político, en la secuencia "El matadero", el segundo capítulo de Teoría del alma china, nos encontramos con que el turista se ha vuelto investigador académico, y su misión también es la de redactar un informe sobre un escritor penalizado por el régimen, que vive él mismo en una suerte de colonia penitenciaria.

Confinado en un diminuto departamento, su castigo consiste en asistir diariamente a los estremecedores mugidos soltados por la muerte de vacas, que se oyen por la ventana que da al matadero lindante. Leemos aquí el primer caso de cómo aquí la ley escribe la carne: los “fusilamientos" se encuentran precedidos por un comunicado.

Lo más absurdo siempre era el comunicado.

Era leído sin exclusión a cada vaca "lista” y repetido innumerables ocasiones en tonos diferentes de voz, como si varias personas se relevaran una detrás de otra para condenar entre gritos y gritos a las vacas indefensas. Una vez finalizado este simulacro comenzaba la ejecución (47).

El comunicado da forma a las muertes de las vacas, y aunque de aquellos gritos no se extraiga ningún significado de ley alguna, sí ocurre, como en el relato kafkiano, que el castigo devela su sentido, no mediante el logos sino mediante su misma ejecución. De manera similar, el informe que el investigador escribirá y sus avances serán, a partir de aquí, la propia novela que vamos leyendo, crónica de un viaje en el capítulo anterior. La figura del archivo se reduplica y con ello, la dificultad de representar la empresa del viajero, el conflicto para conocer y abarcar ese espacio en ruinas. La trama se opaca y la China se vuelve un espacio donde las identificaciones y las diferencias entre realidad y ficción pierden valor; al final del apartado, la ficción de archivo y las simulaciones que entraña alcanzan su punto de máxima teatralización. La narración cobra inmediatez, ya que de manera directa leemos el documento que los investigadores exhiben como fruto de su registro: se simula la publicación del "Informe", un documento que "no ha sido hecho para ser publicado" (55). Siguiendo la escenificación del archivo letrado leemos, además, algunos énfasis en su inicio que indican que tal vez deba todavía pasar la censura: "Quisiéramos consignar que nos 
han tratado respetuosamente y nadie nos ha obligado a mostrar este diario. [...] Estamos seguros que la benevolencia de la ley será la única que caerá sobre nosotros" (55-56). A continuación sigue una lista de 28 apuntes en donde progresivamente se documentan desde los sucesos observados en la casa del escritor, las desapariciones del archivo y obstaculizaciones en la investigación ("han desaparecido 11 cajas de textos", 56), a las entradas de un diario y el descubrimiento de una máquina registradora, que había espiado adentro de la casa y que los ha espiado a ellos'. El hallazgo del aparato resulta el espacio del Archivo, sus fotos permiten sospechar un revés absoluto de la trama narrada hasta el momento: en esta otra historia el escritor era militar, había colaborado con el régimen, había matado vacas y gorriones ${ }^{10}$. Lo que abre así el informe, es una multiplicación de la sospecha, desmoronando por entero la posibilidad de sostener la veracidad del Archivo como espacio de resguardo del saber (Derrida, 1997). En su lugar, la noción que los investigadores deciden manejar pone en juego la idea foucaultiana que mencionábamos al principio, una conceptualización del archivo como operatoria y como praxis de regulación de los enunciados: "Decidimos que debemos regresar al hospital y mostrarnos como si-nuncahubiéramos-sospechado-nada. Un verdadero profesional simula incluso hasta cuando cree que ha sido descubierto" (63).

\footnotetext{
9 "En uno de los rincones de la sala hay un aparato. Es metálico, con varios bombillitos rojos y una bocina en forma de cono; por uno de sus extremos bota papeles" (57). "El aparato está registrando lo que ahora mismo hacemos. Reproduce imágenes detalladas de nuestros movimientos por la casa y va describiendo a pie de foto nuestras acciones. Por ejemplo: Si nos sentamos a leer el diario del escritor dice: Occidentales sentados leyendo diario. 19.07 gmt." (58).

10 "Junto a los papeles del escritor aparecen muchas cosas que no habíamos "registrado" antes: brazaletes de soldado, medallas militares, fragmentos de notas aparecidas en la prensa, una pequeña pistola semioxidada o que por lo menos no se limpiaba hacía mucho, una portada de revista donde se ve al escritor sonriendo encima de una montaña de gorriones disecados" (60). "Bajo el sofá descubrimos otras cajas con fotos: con la misma calidad de impresión del aparato. En algunas aparece el escritor disfrazado de militar en el patio del matadero ordenando la ejecución de las vacas y, en otras, con su rostro muy cercano al de varios de estos animales como si estuviera susurrándoles algo. En un álbum, el escritor y la Pekinesa pintan y recortan los hombrecitos de cartón. Sonríen" (59). Es posible leer en los gorriones muertos una reminiscencia histórica: la matanza de gorriones realizada por Mao Tsé-tung en 1958 como parte del programa de exterminación de plagas, que traería luego una tremenda invasión de langostas, - a tal punto que hiciera falta años después repoblar los campos de aves. Esta matanza masiva es el núcleo del poema "Mao", un poema anterior del autor, publicado en el Nº 1 de Diáspora(s) en 1997 (Aguilera, 1997b).
} 
Si la función del archivo como documentación de una verdad queda entre signos de pregunta, la investigación del narrador permite pensar, finalmente, que por detrás de la descripción más pormenorizada y detallista de la maquinaria moderna ("la maquinita historia", 39), una matriz humorística e irracional la sostiene. En la escritura de Aguilera esto no sucede en virtud de un develamiento de lo oculto, sino, justamente, por la exposición apasionada del detalle. Se trata de una mirada obsesiva del autor sobre los cuerpos que acaba por deformarlos. Convertidos en monstruos, los cuerpos se encuentran con un aspecto animal, que los extrae de lo figurable y los conduce al extremo opuesto del encierro. En un sentido, la letra apunta a registrar lo vivo, hasta sus seres más deformes (tal es el caso del apartado "El Gran Corazón de Occidente", que tematiza el documentalismo del Alemán, un personaje que habría precedido a Werner Herzog, sobre los modos de vida de los enanos). La China de Aguilera, empezando por la metáfora del Matadero, se encuentra colmada de animales. La cuidadora del escritor, ambiguamente llamada "la Pekinesa", vive con él en el edificio, una "trampa para ratones" (39). Recortes de animales cubren las paredes, gorriones disecados lo decoran y, por supuesto, se desborda la presencia de las vacas, cuyas muertes el escritor estudia pormenorizadamente ${ }^{11}$. La novela que encuentran, entre sus papeles inéditos escondidos, se llama Animales en movimiento (45), así como gorriones de juguete que esconden grabadores (60). En los fumaderos de opio también hay animales, así como en el museo de guerra y en muchos otros momentos, la cantidad de animales que se dan cita en la novela es vasta. En principio, su aparición sucede en el marco de una descripción panorámica, como efectos de una percepción que se entromete y rompe con la convención del paisaje:

${ }^{11}$ Las anotaciones de su diario reduplican el ojo detallista del autor: "En realidad los matarifes desuellan muy rápido a los toros, como si con esa rapidez quisieran economizar su dolor. Con las vacas se demoran más. Les cortan primero las ubres y después el rabo en tres pedazos. Posteriormente con un cuchillo las van apuñaleando hasta que la vaca se desangra". Otra página: "A los toros los matan con electricidad. Dos o tres cablecitos alrededor del cuerpo y una descarga. Lo más curioso es que siempre caen con los ojos cerrados, como si no quisieran culpar a nadie. Las vacas no. Las vacas caen con los ojos abiertos o pestañeando. Más de una vez he visto como los matarifes les echan chorros de agua en los ojos para ver si los cierran". Otra página: "Por la manera en que mueren los toros y las vacas sabemos que son animales en diferencia" (57). 


\begin{abstract}
A los fumaderos también asisten mujeres, aunque con ellas sucede algo curioso: se les suministra gratis el opio con la obligación de subir tiempo después a un estrado y narrar lo que observan. Así, cuando nosotros estábamos ya consumiendo el opio de la excitación, una mujer aseguró "ver" un caballo que daba vueltas alrededor de un árbol que en vez de frutos paría ratones. La imagen de un ratón (o una rata) colgada de una rama me dejó pensando y empecé a olisquear ratones por todas partes: ratones grúas y ratones martillos, ratones hachas y ratones bocas, que mordían y se abalanzaban sobre mí enseñando los dientes. Uno de ellos dijo: "Yo estoy por encima del concepto ratón", e intentó cortarme el brazo (24).
\end{abstract}

Sin embargo, en un segundo sentido más radical, surgen como consecuencia de una mirada obsesiva, cuyo detalle conduce a la deformación de las figuras humanas. Así, por ejemplo, el investigador llega a confundir en la imagen de un gorrión a la cuidadora del escritor, desbaratando no sólo la división entre animal y humano, sino a su vez, entre lo muerto y lo vivo. A fuerza de observar el gorrión fijamente, una mueca lo lleva a un rostro:

El gorrión tiene una expresión muy rara en el rostro. Sus ojos y cierta apertura en el pico, como si quisiera decir algo, recuerdan los ojos y la boca de la Pekinesa. Es como si el artesano que lo momificó se hubiera basado en una foto de ésta. Quizá, en una foto de la Pekinesa joven. Por momentos, no sabemos cómo ni por qué, el gorrión mueve una pata (56).

El efecto de la mirada fija es progresivo; va desde la descripción de una figura hacia su desfiguración o animalización. Tal es el caso del propio escritor, su casi conversión en monstruo al ser hospitalizado. Lo mismo ocurre con la descripción del presidente de la Bolsa:

Narró las varias etapas que había tenido esta nueva recaída: primero con manos viradas-lengua afuera, después con suplemento de oxígeno-ojos en blanco, más tarde con espumarajos babosos-contorsiones epilépticas, y cómo desde hace dos días todo se había controlado y empezaba a mejorar. Si continúa así, graznó, estaremos muy pronto en nuestra casa (54, el destacado es mío).

El presidente era gordo, zambo, de uñas largas, con una sonrisita perenne y gestos afeminados. Ladraba tan enredadamente que muchas veces 
se perdía y al final ya nadie sabía qué estábamos hablando. Cuando miraba daba una extraña impresión de peep-show (48).

Un peep-show, esa cámara interna que desde una mirilla le exhibe a un ojo una imagen desmesuradamente aumentada, ubica el procedimiento para la escritura, que devuelve los pasajes de máxima opresión del poder sobre los cuerpos como formas alternas, animalizadas, o desfiguradas. Si bien estos devenires animales deben ser leídos en consonancia con la influencia que recayó sobre los escritores reunidos en torno a la revista Diáspora(s) de la filosofía de Gilles Deleuze y el posestructuralismo ${ }^{12}$, estas intensidades de la mirada sobre los cuerpos y sus metamorfosis también pueden ser leídas como condensaciones poéticas que resuelven o elaboran -en un tiempo posterior al de los proyectos del comunismo, indisolublemente ligados a la idea de progreso moderna (Buck Morss, 2004)- el conflictivo pasaje que Michel Foucault (2002) señalara entre las políticas de la vigilancia sobre cada cuerpo individual, y las potencias de las vida, esto es, los impulsos que lo viviente imprimía productivamente para su administración, reproducción y resguardo.

Si los restos de la modernidad se reescriben en este Oriente canónico, serían entonces dos los procedimientos que utiliza Aguilera para marcar sus ruinas. En primer lugar, la reconstrucción exhaustiva de los dispositivos de encierro y vigilancia: las penitenciarías, los museos, las colonias, los mataderos. Sitios de reunión y recolección de lo vivo, de separación y clasificación, de sacralización y muerte. En el marco de esos constructos, se toma la forma, cabal, determinada, clara, del informe, el expediente poli-

${ }^{12}$ La revista Diáspora(s) en cuyo núcleo de coordinación se encontraba Aguilera, funcionó entre 1997 y 2002. Sostenía un punto de vista sumamente crítico en relación a las políticas culturales vigentes en ese momento, buscó una reivindicación de la vanguardia, una “poesía (sin)táctica de guerra”. En líneas generales buscaron recuperar autores cubanos no reconocidos por aquellos años por el régimen (como Lorenzo García Vega, Severo Sarduy o Virgilio Piñera), al igual que el retomar prácticas conceptuales o vanguardistas, apartadas de las reglas del arte del realismo socialista, y utilizar así el legado de las intervenciones teatrales y de acciones efímeras de los años sesenta, bajo una serie de reflexiones acerca del lugar intelectual en el declive de la modernidad, algo que el grupo Diáspora(s) reunía mediante los aportes del posestructuralismo y de los escritores del "deshielo" soviético. Sobre la revista Diáspora(s) ver los trabajos de Idalia Morejón Arnaiz (2012 y 2015) entre otros, de Guadalupe Silva (2015) y la edición crítica y facsimilar confeccionada por Cabezas Miranda (2013). 
cial o académico, la letra clavada sobre los cuerpos que habrá de ser elevada a una autoridad, poniendo en juego el archivo latinoamericano como sustrato formal de la ficción (según el trabajo mencionado de González Echevarría), así como las teorías kafkianas de la letra y el castigo. Para recuperar las palabras de Severo Sarduy, se trata de una escritura del cuerpo, pero menos en el sentido de ornamentación y performance, que en el de sometimiento a la violencia: nunca se vuelve inteligible salvo por su puesta en acción. Sin embargo, en una segunda instancia, la mirada del narrador, en su veloz pasaje del turista ingenuo al investigador académico, se oprime sobre los cuerpos y las cosas, focalizándolos al punto de conducirlos hacia su deformidad, lo cual es, a su vez, su salida, el paso siguiente de esta poética, que reside en la conversión de los humanos en animales, de los sonidos en onomatopeyas, de los objetos en fuerzas monstruosas. Del encierro a lo abierto, las teorías orientales de Aguilera indican desplazamientos que suponen, ante todo, fugas de un archivo totalizador.

\section{Referencias}

Aguilera, C. (1996). Retrato de A. Hopper y su esposa. La Habana: Ediciones Unión.

. (1997a). Das Kapital. La Habana: Ediciones Abril.

. (1997b). Mao. Diáspora(s), 1, 22-24.

. (2006). Teoría del alma china. México: Libros del umbral.

Antelo, R. (2001). Moscou. Marco do moderno. En Transgressão e modernidade (pp. 218-232). Ponta Grossa: Editora UEPG.

Buck Morss, S. (2004). Mundo soñado y catástrofe. La desaparición de la utopía de masas en el Este y el Oeste. Madrid: A. Machado Libros.

Cabezas Miranda, J. (comp.) (2013). Revista Diáspora(s). Edición Facsímil (1997-2002). Barcelona: Lingkua.

Derrida, J. (1997). Mal de archivo. Una impresión freudiana. Madrid: Trotta. Díaz, D. (2013). La revolución congelada. Madrid: Verbum.

Foucault, M. (2002). Derecho de muerte y poder sobre la vida. En Historia de la sexualidad. 1. La voluntad de saber (pp. 161-194). Buenos Aires: Siglo XXI.

. (2013). Arqueología del saber. Buenos Aires: Siglo XXI.

González Echevarría, R. (2000). Mito y archivo. Una teoría de la narrativa latinoamericana. México: Fondo de Cultura Económica. 
Kafka, F. (1976). En la colonia penitenciaria. En Informe para una Academia y otros cuentos (pp. 25-46). Buenos Aires: Centro Editor de América Latina.

Link, D. (1997). Tánger, ruina de la modernidad. Cuadernos Hispanoamericanos, $565,159-176$.

Loss, J. (2013). Dreaming in Russian. The cuban soviet imaginary. Austin: University of Texas Press.

Mateo Palmer, M. (1995). Ella escribía poscrítica. La Habana: Editora Abril.

Morejón Arnaiz, I. (2008). Nuevo exotismo: escritores latinoamericanos en tránsito. Actas XI Congresso Internacional da ABRALIC. São Paulo: Universidade de São Paulo.

. (2011). Nativos excéntricos. La subversión de la nacionalidad. Crítica, 143, 147-160.

. (2012). Diáspora(s): memoria de la posguerra. Crítica, 148, 55-59.

. (2015). Pater familias por una literatura menor: la poética conceptual del grupo Diáspora(s). Revista Brasileira do Caribe, vol. XVI, 30, 195-205.

Puñales Alpízar, D. (2013). Escrito en cirílico. El ideal soviético en la cultura cubana posnoventa. Santiago de Chile: Cuarto Propio.

Rojas, R. (2009). Souvenirs de un caribe soviético. En El estante vacío. Literatura y política en Cuba (pp. 41- 65). Barcelona: Anagrama.

Said, E. (2002). Orientalismo. Barcelona: Random House-Mondadori.

Saítta, S. (2007). Intelectuales argentinos en la Unión Soviética. En Octubre rojo: la revolución rusa noventa años después (pp. 79-93). Buenos Aires: Libros del Rojas.

Sepúlveda, C. (1996). La imagen de Oriente en las novelas de Severo Sarduy. Inti, Revista de Literatura Hispánica, 43, 135-145.

Silva, G. (2015). La isla erosionada. El proyecto Diáspora(s) - Cuba, 19972002. El Jardín de los Poetas. Revista de teoría y crítica de poesía latinoamericana, 1. Disponible en http://cajaderesonancia.com/jardin-detalle. php?id=103.

Steiner, G. (2000). Extraterritorial: ensayos sobre literatura y la revolución del lenguaje. Buenos Aires: Adriana Hidalgo Editora.

Valdecantos, A. (2009). Una biopolítica afirmativa. Entrevista con Roberto Espósito. Minerva, 12, 68-71. 